\section{UK professional bodies sign and publish evidence declaration}

On 7 November 2017 heads of UK professional bodies publicly signed and published an evidence declaration, with a further aim to embed the declaration principles within the strategic objectives of their institutions.

The evidence declaration signing was hosted by the Alliance for Useful Evidence and Professor Jonathan Shepherd CBE, Royal College of Surgeons and Cardiff University, and chaired by Lord O'Donnell. The event focused on the sustainability of commitment to the evidence declaration and how to ensure the values proclaimed therein are built into the foundations of these national institutions.

In the document the professional bodies declared that their institutions expect all members to take full account of evidence and evidence informed guidance in their daily decisions and advice to individuals and organisations. It also declared that those institutions expect and will support rigorous evaluation.

Professor Jonathan Shepherd CBE said: 'Professional bodies are major influences on the daily practice of hundreds of thousands of professionals across the UK who are their members and fellows. Through their conditions of membership, training and continuous professional development provision, and policy making, these institutions drive evidence adoption. This evidence declaration signals commitment to building these standards on the foundations of quality assured evidence?

\section{BOOK REVIEW}

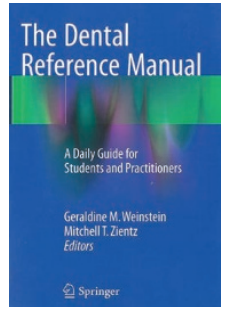

THE DENTAL REFERENCE MANUAL: A DAILY GUIDE FOR STUDENTS AND PRACTITIONERS Geraldine M. Weinstein and Mitchell T. Zientz Springer

2017

price $€ 88$ pp. 530

ISBN: 9783319397283

The Dental Reference Manual aims to be a succinct guide to general dental practice that is suitable for both students and early practitioners. Each chapter is authored by experts and educators in the field and is evidenced with a reference list which may assist readers with researching the topics further. The book has excellent colour photographs and images to support the text.

It is segmented into four sections with the first covering dental practice essentials such as local anaesthetic and occlusion management. A particular strength is that it covers more recent developments in dental technology such as implants and CAD/ CAM techniques for indirect restorations. This is followed by the dental specialties section where the chapters, including oral pathology and orthodontics, are pitched at a level suitable to general practice and are not excessively detailed.

The third section looks at everyday dentistry including sections on prescribing, liaising with dental laboratories and

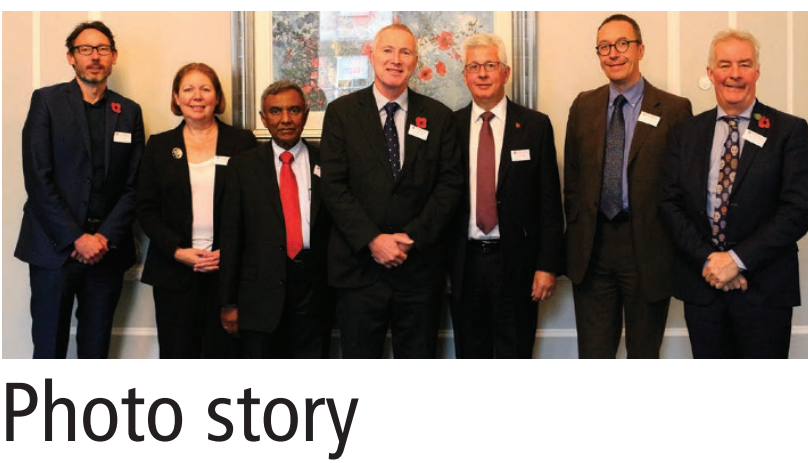

Pictured are some of the speakers at the Mouth Cancer conference, held at the Royal College of Physicians \& Surgeons of Glasgow on 3 November 2017. From left to right: Professor David Conway, Dr Petrina Sweeney, Professor Saman Warnakulasuriya (Ben Walton Trust Lecturer), Professor Graham Ogden (Vice President [Dental] \& Dean of the Dental Faculty), Professor Paul Speight, Dr John Brunton and Professor Mike Lewis. It was a busy day for the Dean, with the AGM and then annual dinner capping an end to his first year as Dean.

\section{Notice of deaths}

It is with sadness that we note the deaths in December 2017 of Professor H. S. M. Crabb and Professor Martin Hobdell.

medical emergency management from a dental practice perspective. However, many of the drug choices, laws and guidelines referenced are specific to the United States of America and do not necessarily directly correlate to British practice. These aspects are of real significance to practising clinical dentistry and make this text appear to be of great value to American general dental practitioners, but limits the usefulness to dentists practising in the United Kingdom and other nations.

The final section looks at how four practitioners have carved out careers, from being involved in creating a new dental school, working for the US President, developing a private practice and embarking on a career from training in Zimbabwe. This content deviates off-piste from the apparent aims of the book as these chapters do not provide any clear value to an individual's daily practice of dentistry. Nonetheless, they are interesting and well-written, giving insight into the varied pathways that a dentist can take.

In summary, I feel this book would be a good reference tool for American dental students from the clinical part of their training through to entering general practice as qualified dentists. It may also be of some interest and worth to graduate American dentists as it evidences up-to-date guidelines and literature. However, this American perspective may be confusing for British dental students or practitioners and there are other British-authored general dental guides that would be of greater value as a summative reference text.

Claire Wilson 